\title{
Algunas reflexiones sobre el Estado y la seguridad pública
}

\author{
Some reflections on the State and public security
}

\section{Jaime Rubén Sapolinski*}

\begin{abstract}
* Doctor en Derecho y Ciencias Sociales y profesor adscripto en Derecho Constitucional (títulos de la Facultad de Derecho, Universidad de la República, Uruguay). Profesor de Derecho Constitucional en la Universidad CLAEH. Profesor agregado de Derecho Constitucional en la Facultad de Derecho de la Universidad de la República. Profesor de Derecho Público en la Universidad de la Empresa. Asesor letrado del Ministerio de Educación y Cultura. $\triangle$ jsapolins@gmail.com
\end{abstract}

http://orcid.org/0000-00022186-0224

\begin{abstract}
Resumen
El artículo intenta formular un conjunto de reflexiones referidas a la problemática de la seguridad pública y al papel que le cabe al Estado a dicho respecto. Se propone un análisis realista sobre el mencionado asunto, evitando incurrir en afirmaciones basadas en paradigmas que podrían resultar opinables. Incorpora un planteo que alude al rol de la fuerza pública, así como al de los otros agentes públicos con responsabilidades en la materia.
\end{abstract}

Palabras clave: seguridad humana, seguridad del Estado, Estado, delincuencia, conflicto social.

\begin{abstract}
This article attempts to debate on public security and the role of the State in that matter. A realistic analysis is proposed, avoiding claims based on arguable paradigms. The role of the public force is considered, as well as that of other public agents with responsibilities on that issue.
\end{abstract}

Keywords: human security, state security, state, delinquency, social conflicts. 
Art. 4 - Como el objeto y fin del Gobierno debe ser conservar la igualdad, libertad y seguridad de los ciudadanos y de los Pueblos, cada Provincia formará su Gobierno bajo esas bases, a más del Gobierno Supremo de la Nación. (José Artigas. Delante de Montevideo, 13 de abril de 1813)

\section{Situándonos en el problema}

1. Hay descripciones de la realidad que son útiles, a título de hipótesis. No quiere decir que la situación sea precisamente esa, la descrita, sino que se aporta un diseño que contribuye a referir las circunstancias que son solamente abarcables de modo parcial. Un pensador determinado no es un profeta; simplemente realiza un aporte que ilumina el conocimiento de los hechos hasta que se demuestra que la descripción es poco útil y debe ser sustituida por otra. En síntesis, de eso se trata el método científico, siempre provisorio, siempre revisable, que contraría los dogmas inconmovibles. No se puede describir la verdad última, que es, probablemente, inabarcable. Se procura solamente dar una explicación plausible que sirva para abordarla y predecir consecuencias. Un día se descubrió que el modelo heliocéntrico de Copérnico es más plausible que el anterior, y el geocentrismo de Ptolomeo terminó siendo rotundamente desmentido. En las ciencias sociales, es más factible que haya explicaciones que a veces cuadren y otras veces no, en función de lo que sucede en la realidad. Por ejemplo, la doctrina de la lucha de clases o la de la soberanía popular pueden resultar útiles en ocasiones para dar cuenta de una determinada realidad. Es la realidad la que se trata de comprender; la explicación debe ser fiel a esa realidad y no corresponde distorsionar la imagen de esta para que se adecue a una concepción determinada.

2. Las hipótesis, en el sentido mencionado, constituyen paradigmas. ¿Qué es un paradigma en lo que refiere a los temas sociales? Es un modelo, una explicación, una mirada, sesgo o perspectiva desde la que se percibe e interpreta la realidad social. Frecuentemente comprende pautas de origen remoto que implican valores. Es decir que contiene la convicción de su valía. Si se profesa una determinada creencia que procura explicar la realidad y legitima las conductas seguidas, estaremos en presencia de un paradigma que se nutre, seguramente, de algo de información y mucho de prejuicio, que incluye pautas de conducta tradicionales y explicaciones mitológicas. ¿Cuánto hay de realidad y cuánto de superchería en las motivaciones de una conducta? Es una pregunta difícil de contestar. Lo cierto es que esas concepciones constituyen bases que justifican conductas y actitudes, y sostienen los roles, las posiciones y los privilegios de los diferentes actores en el medio social. Sirven para ubicarse, conseguir oportunidades y satisfacer las aspiraciones de los involucrados. 
3. Dentro de los citados paradigmas aparecen ideas tales como la de la natural bondad de la gente, incluido el mito del buen salvaje -intrínsecamente incontaminado, pero capaz de pervertirse con enorme facilidad-. Podría también considerarse como paradigma la existencia de un creador bondadoso y paternal, que dicta reglas sagradas, a cuyo servicio opera una especie de burocracia, igualmente imbuida de espíritu altruista y que tiene ganada cierta preeminencia en función de su vocación y conocimiento de las normas dictadas. Similar papel puede jugar un líder carismático de imagen paternal: el Gran Hermano de George Orwell, ${ }^{1}$ por ejemplo. Hoy empleamos la denominación populismos para describir determinadas tendencias de gobierno y sus relaciones con la población en que se manifiesta una propensión a confundir roles, a divinizar a algunos políticos, por ejemplo, en concepción por la que la conducción de la cosa colectiva se somete a una especie de sacrosanto ser providencial cuyas miserias se tratan de ocultar.

Lo sagrado puede definirse como lo que debe protegerse, no se discute ni manosea ni contamina y su administración queda en manos de sacerdotes especializados. Sagrados son los dogmas y las bases ideológicas en que se sustenta un sistema social, tan funcionales a la hora de satisfacer ciertas ambiciones y tan útiles para alcanzar algunos privilegios.

4. Los modelos aplicados a la vida social son difíciles de desmentir en forma contundente. Dan cuenta de una parte de la realidad y, según la porción que se visualiza, podrá considerarse, con cierto facilismo, que una premisa está demostrada, sin discusión, olvidando la tremenda complejidad de los hechos. Los hombres no son bondadosos en general, pero algunos sí lo son. No todos los sacerdotes de las diferentes creencias ni los políticos que pretenden conducir los destinos públicos son personas impolutas, pero existen quienes ejercen su ministerio de modo ejemplar.

5. La idea de la suprema bondad de los seres humanos constituye un paradigma que se conecta, íntimamente, con la concepción democrática. La gente es buena, está bien inspirada, y no se equivoca y, por eso, los elegidos de la mayoría deben conducir los destinos colectivos. Los errores individuales se compensan y la resultante es infalible, como sostiene Jean Jacques Rousseau en El contrato social. ${ }^{2}$

1 Referencia a la novela distópica de Eric Arthur Blair (escrita bajo el seudónimo de George Orwell) 1984, publicada en 1949 (Orwell, 1949).

2 «Libro II. Capítulo III. Sobre si la voluntad general puede errar.

"Se sigue de todo lo que precede que la voluntad general es siempre recta y tiende a la utilidad pública; pero no que las deliberaciones del pueblo ofrezcan siempre la misma rectitud. Se quiere siempre el bien propio; pero no siempre se le conoce. Nunca se corrompe al pueblo; pero frecuentemente se le engaña, y solamente entonces es cuando parece querer lo malo.

»Hay, con frecuencia, bastante diferencia entre la voluntad de todos y la voluntad general. Esta no tiene en cuenta sino el interés común; la otra se refiere al interés privado, y no es sino una suma de voluntades particulares. Pero quitad de estas mismas voluntades el más y el menos, que se destruyen mutuamente, y queda como suma de las diferencias la voluntad general. 
6. Sin embargo, esa idea de la suprema bondad natural parece endeble en grado superlativo. El egoísmo, el arrebato, la rapiña y el abuso constituyen una regla que se cumple con enorme frecuencia. Seguramente fue esa la tónica de la conducta de los antropoides originales seguida en los centenares de miles de años desde que estos y sus descendientes circulan por el planeta. ¿Cambiaron las cosas en los últimos diez mil años? No demasiado.

7. Stanley Kubrick (1968) describe, en el principio de 2001. Odisea del espacio, el paso hacia la humanidad mediante el cual un grupo de nuestros antepasados remotos consigue dominar a una tribu rival, integrada por individuos semejantes, recuperando un ojo de agua del que dependía su sobrevivencia. Descubrieron que los huesos pueden ser blandidos como armas y ese primer avance tecnológico fue el que les permitió vencer a sus rivales. Esa ficción nos brinda la crónica de un arrebato, de una usurpación y de un homicidio. Fue un acto de guerra. ¿Cuánto hemos evolucionado desde esa etapa? Temo que menos de lo deseable.

8. Los individuos de nuestra especie fuimos originalmente depredadores, como se intentó reflejar en la obra cinematográfica mencionada. Nos condujimos, al principio y en la mayor parte de nuestro transitar como especie por el mundo, en función del instinto posesivo, del abuso de la fuerza, del odio, la venganza, la avaricia y de la ambición sin freno. ¿Hasta dónde la sofisticación posterior nos ha hecho superar y desestimar esos impulsos? ¿Hasta dónde las proclamaciones de justicia, integración y solidaridad social, democracia, cultivo intelectual, etcétera, han sido un dique adecuado a esos impulsos desbordados? ¿Hasta dónde son expresiones honestas las manifestaciones de solidaridad y respeto por el derecho que se hacen con frecuencia, para borrar con el codo lo que se ha escrito con la mano? Lamentablemente, no hemos conseguido erradicar ni el espíritu tribal ni el abuso ni la corrupción. Allí tenemos, como lastre contra una mirada optimista, a los acomodaticios de todos los tiempos prontos a sostener un sistema inmoral, a los autoritarios, a los colaboracionistas y a los coimeros.

9. Y además de lo que llevamos innato, no descartemos las conductas aprendidas que fortalecen las tendencias primigenias. Se ha señalado la existencia de culturas primitivas que conviven en armonía, aunque ello sucede en la medida en que las pocas necesidades se logren satisfacer (Aronson, 1992). ${ }^{3}$ No sé si se nace cazador; en todo caso, también se aprende a serlo.

10. En definitiva, además de las diferencias en cuanto a la apariencia física, los seres humanos hemos conseguido desarrollar la corteza cerebral, de surgimiento tardío en la evolución, en la que se centran la percepción, la imaginación, el pensamiento,

»Si cuando el pueblo delibera, una vez suficientemente informado, no mantuviesen los ciudadanos ninguna comunicación entre sí, del gran número de las pequeñas diferencias resultaría la voluntad general y la deliberación sería siempre buena» (Rousseau, edición 2007, p. 58). 
el juicio y la decisión. La última porción, la isocorteza, es desde donde concretamente parten el raciocinio y la conciencia. Allí está la auténtica condición humana, que nos distingue del resto de los animales. Por allí están situados la moralidad, el sentido jurídico, las pautas de convivencia, etcétera. Sin embargo, ¿cuántas de las funciones racionales son susceptibles de un mejor desarrollo derivado del estímulo y la integración social y cuánto puede ser atrofiado como consecuencia del desuso de las funciones cognitivas o de la intoxicación?

No hemos superado totalmente la condición primitiva que nos sigue condicionando. El espectáculo de la fiera que protege su hueso y gruñe cuando teme que se lo arrebaten nos describe bastante bien. Finalmente, el buen salvaje es un mito. Ese que sometía a su prójimo, lo sacrificaba en ceremonias absurdas, lo esclavizaba o lo aniquilaba nunca fue tan bueno. Era, también, un ser humano, parte de la especie. Igual a los demás, en lo sublime e igual a los demás en la maldad.

Sigmund Freud decía en 1930 (trad. 2005), en El malestar en la cultura:

La verdad oculta tras todo esto, que negaríamos de buen grado, es la de que el hombre no es una criatura tierna y necesitada de amor, que solo osaría defenderse si se lo atacara, sino, por el contrario, un ser entre cuyas disposiciones instintivas también debe incluirse una buena porción de agresividad. Por consiguiente, el prójimo no le representa únicamente un posible colaborador y objeto sexual, sino también un motivo de tentación para satisfacer en él su agresividad, para explotar su capacidad de trabajo sin retribuirla, para aprovecharlo sexualmente sin su consentimiento, para apoderarse de sus bienes, para humillarlo, para ocasionarle sufrimientos, martirizarlo y matarlo. Homo homini lupus: ¿quién se atrevería a refutar este refrán, después de todas las experiencias de la vida y de la historia? Por regla general, esta cruel agresión espera para desencadenarse a que se la provoque, o bien se pone al servicio de otros propósitos cuyo fin también podría alcanzarse por medios menos violentos. En condiciones que le sean favorables, cuando desaparecen las fuerzas psíquicas antagónicas que por lo general la inhiben, también puede manifestarse espontáneamente, desenmascarando al hombre como una bestia salvaje que no conoce el menor respeto por los seres de su propia especie. Quien recuerde los horrores de las grandes migraciones, de las irrupciones de los hunos, de los mogoles bajo Gengis Khan y Tamerlán, de la conquista de Jerusalén por los píos cruzados y aun las crueldades de la última guerra mundial tendrá que inclinarse humildemente ante la realidad de esta concepción.

A veces, lo único que falta para canalizar el impulso a la rapiña es un débil detonador. Puede ser una doctrina o un mensaje mediático, cualquier cosa que justifique 
por qué es posible robarle al vecino. Es conocido el experimento de Stanley Milgram, en la Universidad de Yale, que mide hasta dónde alguien puede obedecer una orden de quien parece ser la autoridad legítima, llegando a emplear métodos aberrantes, concretamente descargas eléctricas simuladamente dolorosas aplicadas a un sujeto, un actor, que expresa un dolor insoportable (Milgram, 1980).

11. El problema de la seguridad pública tiene mucho que ver con lo antes referido. La inseguridad es consecuencia de la acción de depredadores que, evidentemente, violan las estipulaciones de un supuesto contrato social, el cual presupone la existencia de derechos y la existencia de una organización estatal y tiene por finalidad asegurar la vigencia de aquellos.

12. La inseguridad es hija de la miseria; pero no solo de la miseria material que, por otra parte, se reproduce por causas culturales. No es cierto que se puedan combatir ambas, la inseguridad y la miseria, mediante una simple redistribución de recursos. No alcanza con disponer de una especie de Robin Hood que les saque a los ricos para darles a los pobres, porque, por ejemplo, muchas veces quien se encuentra carenciado se reproduce en forma descontrolada y con ello permanece en la pobreza y la multiplica, así como las pautas culturales que la favorecen. Tampoco es del todo cierto que la inseguridad sea una reacción defensiva de quienes poco tienen, porque allí está el crimen organizado para desmentirlo. No es que se tenga poco, se trata de tener más; en lo posible, más que el otro.

13. «Somos buenos pero la sociedad nos corrompe» probablemente sea un paradigma falso. Quizás la respuesta es que somos malos y, por eso, generamos organizaciones sociales que confieren una forma de legitimidad diferente de la que brinda el Estado. Porque la mara, el gang, la banda son también estructuras sociales. Todo factor coadyuvante a la inseguridad debe ser tenido en cuenta, pero una descripción no sería completa si no nos sumergiéramos en las profundidades de la mente humana, precisamente en lo menos humano de su composición.

14. El Estado expresa, formalmente, un determinado ordenamiento que es permanentemente desafiado. Allí tenemos lo sucedido en el Casavalle, los tiros, la usurpación de domicilios y el enfrentamiento entre los chingas y los camalas, para citar un ejemplo cercano y reciente, entre infinidad de muchos otros posibles. Hace algunos días, cerca de la medianoche, retornaba del dictado de mis clases leyendo en un ómnibus interdepartamental y de pronto una pedrada hizo estallar la ventana. Alguien había salido de cacería... 


\section{El Estado}

15. El Estado es un instrumento diseñado para frenar la anomia, la desviación y la delincuencia. Sin embargo, corresponde una prevención. Quizás no sea correcto hablar de anomia, porque no es que los depredadores mencionados no tengan normas, sino que tienen otras. Otras normas y otros valores, que son alternativos a los generalmente recibidos, hijos de cierta forma de socialización diferente.

Son normas y valores muy peligrosos, y nos devuelven al paleolítico profundo, a la mencionada escena de Kubrick (1968), a la ley del más fuerte. En una muy comentada entrevista, el director nacional de Policía, Mario Layera (Pereyra, 2018), señala que la autoridad se enfrenta a individuos «por fuera absolutamente del sistema», que incluso hablan en una jerga ininteligible.

Es la parte más extrema de una decadencia que ya la veíamos venir y que comenzó en las cárceles con los extranjeros. Todo empieza en las cárceles. Hay una transmisión de conocimiento permanente con mucha maldad. No hablan de robar, sino que el discurso es la violencia. Si vas a robar no seas gil, el que tenés enfrente es el enemigo. Antes te decían, «está bien, perdí». Ahora se desacatan, atacan, grupos de vecinos que defienden a estos. Hay un choque de culturas que va agravándose. [Hay] problemas en el primer nivel de socialización, que es la familia. Luego no van a estudiar. Tienen generaciones de familiares con antecedentes. Y allí está el mayor nivel de reproducción. Un día los marginados van a ser mayoría. ¿Cómo vamos a contenerlos?

16. El Estado, que se supone tiene por cometido principal sostener un conjunto de normas y valores, cuenta con un aparato burocrático para el cumplimiento de ese cometido. Al frente hay un equipo gobernante que lo conduce, se supone que de manera funcional a los fines debidos. Sin embargo, cabe mencionar que existe, además, un riesgo: el de que las bandas de delincuentes lleguen a encaramarse en el sistema estatal; o sea, la posible presencia de la corrupción en sus diversas manifestaciones. Bertolt Brecht (1941) describe en la La resistible ascensión de Arturo Ui ${ }^{4}$ la conquista del poder de un monstruo que remeda la peripecia de otro monstruo, este lamentablemente real, pero que no fue ni el primero ni el último de su especie. Quizás el real haya sido el engendro paradigmático y haya contado con seguidores encandilados, acaso cómplices y víctimas a la vez. 
17. Thomas Hobbes (trad. 1989) decía en 1651, en El Leviatán, procurando explicar la razón de ser del Estado:

El fin del Estado, la seguridad particular. La causa final, propósito o designio que hace que los hombres - los cuales aman por naturaleza la libertad y el dominio sobre los demás - se impongan a sí mismos esas restricciones de las que vemos que están rodeados cuando viven en Estados, es el procurar su propia conservación y, consecuentemente, una vida más grata. Es decir que lo que pretenden es salir de esa insufrible situación de guerra que, como se ha mostrado en el capítulo 13, es el necesario resultado de las pasiones naturales de los hombres cuando no hay un poder visible que los mantenga atemorizados y que, con la amenaza del castigo, los obligue a cumplir sus convenios y a observar las leyes de naturaleza [...].

Hobbes sostenía que la razón del Estado es evitar la guerra de todos contra todos, o sea, evitar lo que sucede todos los días a minutos de donde estamos situados.

18. El Estado surgió como un mecanismo de contención frente al empleo, podríamos decir, privado de la fuerza. En cuanto a su origen, significó la consolidación de un poder capaz de superar la anarquía encarnada por los diversos caudillos, señores feudales o como se los llame. El sistema feudal es visto como una forma de organización preestatal. La existencia del Estado sería un paso evolutivo.

Entonces, procurando superar el feudalismo, se estableció la idea de que había que instaurar un poder supremo, un soberano que mandara lo suficiente para consagrar un orden con vocación de ser irresistible. Esos regentes absolutos consolidaron su dominio sobre la base del uso discrecional de la fuerza, ejercida mediante la arbitrariedad y el exceso, de un modo quizás ineludible si se consideran las circunstancias. Nosotros mismos, en nuestra propia historia, vimos la consolidación del Estado en la década de 1876-1886, en el período histórico conocido como el militarismo. No tuvimos un Luis XIV, pero sí, en cambio, un Lorenzo Latorre.

Más adelante, a partir de los procesos revolucionarios de finales del siglo XVIII, la idea del ejercicio de la soberanía por un monarca fue sustituida por el concepto de la soberanía del pueblo, o de la nación, tomando ambos términos con un sentido que los asimila. Paralelamente, se entendió que el poder estatal debía ser regulado, por normas generales, claras y aplicables a todos, y esa idea dio lugar a lo que se conoce como Estado de derecho, con gobernantes con atribuciones limitadas y predeterminadas. El poder es, al menos en la teoría, el de las instituciones, no de las personas.

19. ¿Qué es el poder? Es la capacidad de afectar las conductas de las personas. El ejercicio del poder está íntimamente vinculado a la potestad normativa, o sea, a la posibilidad de imponer determinadas conductas, sancionando aquellas consideradas desviadas y haciendo cumplir las debidas, de acuerdo con lo que establece el ordenamiento. 
20. Georges Burdeau (1981, pp. 23-29) expresa:

Los hombres [...] han imaginado otra forma de Poder político. En lugar de considerar que el Poder es una prerrogativa propia del que lo ejerce, han inventado un soporte del Poder que sea independiente de las personalidades gobernantes. Este soporte es el Estado [...].

El Estado es el titular abstracto y permanente del Poder, del que los gobernantes solo son agentes esencialmente, pasajeros.

Sin que sea siempre fácil precisarlo, llega un momento en las sociedades políticas [...] en el que las cualidades personales de un jefe son impotentes para explicar la autoridad que ejerce. La conciencia, política de los súbditos, cada vez más sensible, se niega a pensar que toda la organización social reposa en la libre voluntad de un individuo. [...]

Llamo institucionalización del Poder al acto por el que el funcionamiento del Poder es transferido de la persona de los gobernantes a una entidad: el Estado.

21. El Estado es, ante todo, un magno distribuidor de los recursos que se generan en una sociedad determinada. Contribuye a trasferir los recursos de unos a otros. Tendrá mayor poder en tanto consiga sostener esa idea de distribuidor monopólico, atribuida institucionalmente por las normas que lo rigen. Debe procurar evitar que el poder que ejercen, de hecho, las personas u organizaciones que lo desafían no logre generar un circuito de recursos en paralelo, otra estructura de poder alternativa. A veces estos poderes de hecho, de tipo gansteril, enfrentados al Estado, son inconscientemente favorecidos por este. Por esa razón, y para evitarlo, en ocasiones el Estado ceja, con relación a determinadas prohibiciones, porque reconoce que su actividad de represión termina favoreciendo a los infractores más poderosos, aquellos que son capaces de desafiarlo con más facilidad y a los que les sirve que se reprima a sus competidores. Eso explica, por ejemplo, que la Enmienda XXI de la Constitución estadounidense haya derogado la Enmienda XVIII, conocida como la Ley Seca. 0 alguna argumentación que propugna por la despenalización del aborto o del suministro de determinadas drogas. ${ }^{5}$

Enmienda XVIII

«Sección 1. Un año después de la ratificación de este artículo quedará prohibida por el presente la fabricación, venta o transporte de licores embriagantes dentro de los Estados Unidos y de todos los territorios sometidos a su jurisdicción, así como su importación o su exportación, con el propósito de usarlos como bebidas.

„Sección 2. El Congreso y los diversos estados poseerán facultades concurrentes para hacer cumplir este artículo mediante leyes apropiadas.

„Sección 3. Este artículo no entrará en vigor a menos que sea ratificado con el carácter de enmienda a la Constitución por las legislaturas de los estados en la forma prevista por la Constitución y dentro de 
22. El Estado es una institución que puede parangonarse, alegóricamente, con un buque mercante. Tiene un derrotero, esencialmente determinado por su trayectoria económica, en la que distribuye recursos como quien se dirige a diversos puertos a entregar determinados bienes. Existe, por cierto, el riesgo de naufragar.

En un sistema democrático, quienes se encuentran a bordo son los que eligen a la tripulación y determinan los procedimientos para tal fin. Pueden cometerse errores en la elección, pero nadie puede asegurar que no se cometan en caso de seguir otros mecanismos. Además, es muy complicado mantenerse en el poder si no se cuenta con cierta legitimación: el apoyo social. Y, como dijo Winston Churchill en un discurso pronunciado en 1947: «[...] la democracia es la peor forma de gobierno, excepto por todas las otras formas que han sido probadas de vez en cuando».

23. Ahora, que no todo es agua de rosas. Cito a Gastón Leval (seudónimo de Pierre Robert Pillar), quien desde una perspectiva anarquista mantuvo una visión muy crítica sobre el Estado. Decía en El Estado en la historia, una obra publicada póstumamente, en 1978, el año de su muerte:

El Estado, lejos de ser un instrumento creado para su defensa por las fuerzas económicas que dominan toda la sociedad y condenado a desaparecer con ellas, tiene por el contrario una vida propia, un poder que le permite modelar esa sociedad según su voluntad e influir sobre las relaciones de las distintas categorías sociales de acuerdo con sus intereses. Puede hacer nacer clases nuevas, apoyarse sobre unas para combatir a otras, determinar nuevas formas de explotación y de dominio. Y las afirmaciones de Marx, Engels, Lenin y de algunos de sus discípulos son más utópicas que el socialismo de aquellos a quienes aplicaron desdeñosamente aquel adjetivo. ¿Quién cree hoy en la URSS en el decrecimiento o en la desaparición del Estado, precisamente del Estado marxista? Las clases poseedoras han cambiado, el privilegio económico ha cambiado de forma y de manos, y no hay duda en cuanto a que consolidarán sus posiciones.

\footnotetext{
los siete años siguientes a la fecha en que el Congreso lo someta a consideración de los Estados» (Constitución de los Estados Unidos, enmienda XVIII, ratificada en 1919).

Enmienda XXI

«Sección 1. Queda derogado por el presente el decimoctavo de los artículos de enmienda a la Constitución de los Estados Unidos.

"Sección 2. Se prohíbe por el presente que se transporten o importen licores embriagantes a cualquier estado, territorio o posesión de los Estados Unidos, para ser entregados o utilizados en su interior en violación de sus respectivas leyes.

"Sección 3. Este artículo quedará sin efecto a menos que sea ratificado como enmienda a la Constitución por convenciones que se celebrarán en los diversos estados, en la forma prevista por la Constitución, dentro de los siete años siguientes a la fecha en que el Congreso lo someta a consideración de los Estados» (Constitución de los Estados Unidos, enmienda XXI, ratificada 1933).
} 
24. El Estado desarrolla determinados cometidos esenciales. Son aquellos inherentes a su esencia, que no se conciben sino ejercidos directamente por él (Sayagués Laso, 1988, p. 55). Si el Estado no consigue cumplir con tales cometidos, languidece, tiende a desaparecer, se transforma en un Estado fallido, incapaz de ejercer su poder legítimo en forma adecuada. El mantenimiento del orden y la seguridad constituyen un cometido esencial y así se reclama por la generalidad de la población. Al menos por quienes no participan en un eventual sistema paralelo o alternativo de ejercicio del poder, sí por quienes le reclaman al Estado que les garantice vivir pacíficamente, en el normal ejercicio de sus derechos. La «conservación del orden y tranquilidad en lo interior, y la seguridad en lo exterior» es la primera atribución del Poder Ejecutivo, según lo establece el artículo 168, numeral 1. ${ }^{\circ}$, de la Constitución de la República Oriental del Uruguay (1967).

Hay un riesgo derivado del no cumplimiento adecuado del reclamo de seguridad: que la sociedad se deslice por una vertiente autoritaria, de la mano de algún oportunista, propagandista del orden.

\section{La seguridad pública}

25. El artículo $7 .^{\circ}$ de la misma Constitución, al principio mismo de la declaración de derechos fundamentales, expresa:

Los habitantes de la República tienen derecho a ser protegidos en el goce de su vida, honor, libertad, seguridad, trabajo y propiedad. Nadie puede ser privado de estos derechos sino conforme a las leyes que se establecen por razones de interés general.

Inmediatamente, se consagran el derecho a la igualdad de todas las personas ante la ley (artículo $8 .^{\circ}$ ) y el principio de libertad individual (artículo 10. ${ }^{\circ}$ (Constitución de la República Oriental del Uruguay, 1967).

Adviértase que el artículo 7. ${ }^{\circ}$ hace algo más que proclamar esos derechos fundamentales cuya consagración, ciertamente, compendia la de los demás que se mencionan más adelante. Se establece que deben ser protegidos, que deben ser garantizados. Y, obviamente, el garante es el Estado, no puede ser otro.

Garantizar los derechos supone el ejercicio del poder. El poder rechaza el vacío; si no lo ejerce legítimamente el Estado, alguien lo ejercerá, quizás de la peor forma. ¿Quién si no el Estado? Nos viene a la mente la novela de Mario Puzo y la trilogía dirigida por Francis Ford Coppola, El Padrino. 
26. Pero sucede que el Estado es una organización burocrática en la cual resulta ineludible considerar la acción de los seres humanos que participan y, además, si funciona en forma regulada, si se trata de un Estado de derecho, debe ceñirse a las reglas. No es un justiciero que arregla las cosas a la fuerza y sin límites; ciertas normas y procedimientos constituyen límites que pueden afectar su eficacia, pero contribuyen a evitar injustos daños colaterales. La pregunta inmediata es si es capaz de combatir adecuadamente la anomia, con los medios de que dispone.

27. Y aquí, por casa, ¿cómo andamos?

Es evidente que existe una fuerte preocupación por el incremento de situaciones que comprometen la vida pacífica de las personas.

Ante todo, si bien parece existir una situación diferente, de inusitada gravedad, producto de nuevas modalidades, distintos códigos de conducta, efecto contagio y comercio de droga, tampoco nos encontramos ante una situación completamente novedosa. Es evidente que en toda comparación importan los objetos que se cotejan. Durante nuestro sangriento siglo XIX, por ejemplo, la población era mucho menor en número, pero los episodios de violencia eran, relativamente, muy importantes. Sobre si es cierto que todo tiempo pasado fue mejor, depende de los períodos y lugares que se comparen.

En entrevista de Leonardo Haberkorn (2018), el comisario mayor Sergio Guarteche, exjefe de Policía de Durazno, sostiene que, en materia de seguridad habría que cambiar toda la política.

Hoy en Guatemala el ejército está en la puerta de los supermercados. Esa realidad, tarde o temprano, la vamos a tener. ¿Con qué los vamos a detener? Ya hoy estamos entrando a los barrios con blindados. Falta trabajo a largo plazo. El proceso de baja de la violencia en Nueva York duró 10 años y fue acompañado de un férreo sistema de tolerancia cero, y de medidas complementarias focalizadas en desmantelar el apoyo logístico que alimentaba el crimen organizado y doméstico. Se recuperó la paz y el orden en el subte tomado por las pandillas. Se evacuaron edificios enteros ocupados ilegalmente, se reinició un proceso de urbanización moderno, y muchas medidas más.

Agrega Guarteche:

Hoy existe un combo que alimenta un panorama nada alentador. Hay 130 mil jóvenes que no estudian ni trabajan. ¡Hay entre 6.000 y 7.000 hijos de presos! Hay entre 400 y 600 presos liberados por mes, con un nivel de reincidencia que supera el $50 \%$. Los planes sociales no han dado sus frutos, algo que ya es reco- 
nocido por las autoridades. Y hay un incremento de la violencia armada, el narcotráfico y nuevas modalidades, como el ciberdelito.

De acuerdo, es un diagnóstico, pero ¿hay un remedio? ¿Lo hay para quienes estamos inmersos en una región, notoriamente enferma?

28. En el Diccionario latinoamericano de seguridad y geopolítica, dirigido por Miguel Ángel Barrios (Barrios, Jaguaribe, Rivarola y Calduch Cervera, 2009) se define la seguridad como

[...] el acto de protección que articula un sistema para con su entorno, una condición natural que busca todo ser viviente, organización o colectividad para poder existir, desarrollarse y cumplir sus propósitos en sus múltiples actividades. En un sentido objetivo, mide la ausencia de amenazas para obtener valores, $y$, en un sentido subjetivo, mide la ausencia de temor de que tales valores sean atacados.

29. El concepto de seguridad, en términos generales, se asimila en buena medida al de protección. La seguridad es un escudo que permite resistir los ataques a que se está sometido. La seguridad individual se liga a las garantías del debido proceso. La seguridad social procura encontrar un mecanismo de protección frente a contingencias tales como la vejez, la enfermedad, el desempleo. La seguridad pública, que es el objeto de estas reflexiones, tiene que ver con la protección de los derechos de cada uno, esos que el Estado está para garantizar y proteger.

30. El diccionario mencionado contiene un artículo dedicado a los dilemas referidos a la seguridad. Señala tres problemas con soluciones alternativas y discutibles:

1. La disyuntiva entre la seguridad y el derecho. Una sociedad puede ser más segura pero con menos derechos consagrados, o con más derechos proclamados pero más insegura. En definitiva, se plantea la disyuntiva entre seguridad y libertad, y la oposición entre la posible vulneración de los derechos por el Estado o por actores diferentes. «El desafío de los Estados democráticos es proporcionar una adecuada seguridad sin obstruir los derechos de los individuos», apunta el articulista (Barrios et al., 2009);

2. La disyuntiva entre la seguridad basada en la propia fuerza o en la debilidad ajena. Esto apunta a una tendencia a incrementar los medios de seguridad, en una interacción de tipo carrera armamentista que provoca un incremento en la inseguridad buscando un efecto disuasivo.

3. Un proceso de securitización en el que se admite la adopción de medidas extraordinarias, de tipo coercitivo, ilícitas en condiciones normales. 
31. En torno a la aplicación de paradigmas alternativos o complementarios a los habitualmente sostenidos, acaso en exceso políticamente correctos, podrían aportarse algunas reflexiones que en el fondo son, en buena medida, inferencias de lo ya dicho. Se trata de mantener, ante todo, una mirada realista.

32. La situación de inseguridad deriva del intento de ejercer una dosis de poder y de enfrentar o rivalizar con la actividad del Estado. En el fondo, hay un intento, más o menos consciente, de imponerle otra organización a la sociedad organizada institucionalmente. Por ejemplo, se trata de disputarle a la autoridad institucional la potestad de establecer quién tiene derecho a ocupar determinado inmueble, haciéndolo depender del capricho de algún felón con una mínima dosis de poder fáctico. Es que muchas veces el crimen sí paga.

33. Como en toda actividad en que tiene injerencia el Estado, lo que subyace al reclamo de mayor seguridad pública es una competencia o reclamo por el acceso a los recursos colectivos. Se puede traducir en la brega por una mayor porción del presupuesto nacional, o en un ingreso mejor para determinado grupo de interés, o en el incremento de la carga tributaria para todos o para cierto sector exclusivamente, con las consecuencias sociales que esto conlleva.

34. Para comprender el problema de la inseguridad no es suficiente el paradigma de la bondad esencial de las personas, incluida la afirmación de que, si exceden e infringen las normas, son víctimas que merecen ser apoyadas. La rehabilitación es una finalidad de primer orden que debe ser encarada, pero sin olvidar de que hay elementos que no son capaces de recuperarse, como consecuencia de sus propias características patológicas. No siempre es el resto de la sociedad culpable de su circunstancia. Una ética basada en la responsabilidad exige la asunción de deberes por todos y cada uno. De todos modos, deberemos asumir entre todos el costo de su manutención, justamente por razones de responsabilidad colectiva.

35. El concepto de la igualdad esencial de las personas admite la diferenciación en función de los talentos y virtudes. Quien ha abandonado el contrato social será igualmente protegido por sus estipulaciones, pero acaso no merezca igual consideración que quien rompe con lo establecido porque no es un socio leal. Esto sin olvidar que hay condiciones y circunstancias que pueden atenuar su responsabilidad. La vida de la cajera de la estación de servicio que fue asesinada por un rapiñero vale más que la de su agresor, porque este supone un peligro para sus semejantes, lo que no implica adherir a la tesis del gatillo fácil.

36. Cabe hacer una reflexión sobre la utilidad de los castigos. Corresponde tener presente que como vindicación son prácticamente inútiles, porque los daños causados ya se han producido, y son generalmente irreversibles y no susceptibles de ser reparados infligiendo una pena. Salvo quizás en los pocos casos en que pudieran servir como 
satisfacción moral a la víctima a la que se le ofrece una forma de venganza, lo que es, por otra parte, por demás discutible.

En cuanto a la sanción como medio de rehabilitación, esta es muy difícil en las actuales condiciones sociales. Raramente funciona.

Quizás quede como efecto útil, apenas, la posibilidad de tener al autor del ilícito aislado, procurando atenuar su influencia perniciosa. Pero también esto es relativo, habida cuenta de la información que demuestra que los mafiosos son capaces de conducir sus negocios desde la reclusión.

37. El problema es mucho más que una cuestión policial, sin perjuicio del papel relevante que le corresponde a la Policía en la cuestión. En una obra titulada Pensar la seguridad, Clifford Shearing y Jennifer Wood (2011) reseñan distintas olas referidas al rol de la Policía. Señalan una etapa en que esta ejerce un papel represor, en que la amenaza de coerción «constituye un componente clave de la autoridad legal y simbólica de la Policía». Otra etapa es la de la actuación policial comunitaria, «que fomenta la creación de lazos estratégicos y simbólicos con los ciudadanos comunes». Otra es aquella en que el sistema policial debe ser visto como un «solucionador de problemas» más que como algo que tiene por objetivo mantener el orden público. Otra concepción pasa por analizar la eficacia de los escasos recursos aplicados, buscando llevar a cabo alianzas con otras unidades sociales, tendientes a mejorar la seguridad evitando el dispendio de los recursos públicos.

Cualquiera sea el encare, el empleo legítimo de la fuerza pública constituye un factor ineludible, del que es imposible prescindir.

Quizás a su respecto no sea de descartar la aplicación de mecanismos lícitos, controlados y preestablecidos de estímulo de la productividad de los funcionarios policiales, para tratar de favorecer y optimizar su desempeño

38. El problema es mucho más que un problema carcelario.

Michel Foucault (2016, p. 129) reseña las siguientes críticas a la prisión, «formuladas a partir de todas las disfunciones que la prisión podía inducir en el sistema penal y en la sociedad en general»:

1. La prisión impide al Poder Judicial controlar y verificar la aplicación de las penas.

2. La prisión, al mezclar unos con otros a condenados a la vez diferentes y aislados, constituye una comunidad homogénea de criminales que se tornan solidarios en el encierro y que seguirán siéndolo en el exterior. La prisión fabrica un verdadero ejército de enemigos interiores.

3. Al dar a los condenados abrigo, alimentación, vestimenta y frecuentemente trabajo, la prisión ofrece a los condenados una suerte preferible a veces a la 
de los obreros. No solo no puede tener efecto de disuasión, sino que provoca la delincuencia.

4. De prisión salen personas cuyos hábitos y la infamia con las que están marcadas abocan definitivamente a la criminalidad.

39. La violación de los derechos humanos puede ser producida por cualquiera. Sostener que solo puede ser provocada por los funcionarios estatales es incurrir en un reduccionismo impropio y, quizás, no del todo bien intencionado. Una lesión es tal, cualquiera sea el brazo que la provoca. Debe preservarse a las víctimas del abuso, sea de quien sea, y sobre todo intentar que no las haya. Es preciso encarar mecanismos de prevención.

40. La inseguridad es un fenómeno multicausal y complejo, que no se atiende atacando solo uno de sus ribetes. Por cierto, no es solamente un problema policial, como ya se ha dicho, y conformar un adecuado sistema de educación constituye un camino ineludible. La educación es, por cierto, mucho más que una vía de información; constituye un fundamental agente de socialización que permite generar un terreno adecuado para la convivencia. La educación trasmite valores y desplaza los contravalores que se contraponen. El desorden social, fundamentalmente la marginación y la desorganización del núcleo de base —es decir, de la familia- es antecedente y causa del delito, y sobre dicha inadecuación debería operarse para que los problemas menores no se agranden. Hay un partido que se juega en la cancha del desarrollo social.

41. Además de la función policial, no debe soslayarse la trascendencia del adecuado funcionamiento del Ministerio Público y de la Judicatura. También allí existen riesgos vinculados a la capacidad y al reclutamiento de los agentes. Además, inciden sobre su funcionamiento causas vinculadas a la legislación y a la política criminal, donde las medidas erróneas tienen, obviamente, un costo de dimensiones.

Los partícipes del sistema educativo deben ubicarse también a la altura de su responsabilidad social en la materia.

42. La inseguridad es consecuencia de un fenómeno de fuerza, y este tipo de fenómeno no se previene - al menos no en su mayor parte - con poesía o ideología devaluada. Desgraciadamente, la violencia es una vía de hecho que se contrarresta con fuerza contrapuesta, sin menospreciar los demás caminos concurrentes de cuya eficacia depende en enorme medida la mejora de la situación. Por cierto que la prevención es preferible a la represión, pero no puede despreciarse a la última so riesgo de que tampoco pueda cumplirse con la primera.

Por esa razón, no parece adecuado debilitar o desarticular a la fuerza pública. A efectos disuasivos debe ser puesta de manifiesto cada vez que sea necesario. También hay actividades de inteligencia que resultan inevitables, aunque no guste. 
Contra el adecuado funcionamiento de la fuerza pública conspira la falta de medios. Una vez más aparecen el problema de la escasez de recursos y la teoría de la cobija corta. Y está presente el riesgo de la degradación de los agentes por falta de estímulos, ingresos escasos, los cantos de sirena del consumo y el peligro de corrupción. Quizás pueda concebirse un sistema que premie la eficacia y la productividad para reforzar la vocación de servicio.

43. La fuerza pública debe ser estrechamente controlada para evitar el uso político, el exceso y la corrupción.

Se ha planteado la posibilidad de reforzar la acción policial mediante el concurso de otros recursos estatales utilizables, como, por ejemplo, las Fuerzas Armadas. Por un lado, parece razonable el empleo de medios disponibles en la medida en que efectivamente lo estuvieran, habida cuenta de la necesidad de que cumplan su cometido original, el que, por otra parte, y si se considera el potencial limitado de nuestro Estado en materia de defensa, está concebido para ejercer una función preventiva que comprende actividades de vigilancia, particularmente por parte de la Armada Nacional y de la Fuerza Aérea.

Por otro lado, no puede soslayarse la consideración de los riesgos que entraña colocar a alguien en un contexto diferente al habitual, con posibilidad cierta de contagio de vicios y disfuncionalidades que pueden aparecer en el ejercicio de la función. De buscarse soluciones de este tipo, deberían aplicarse fuertes controles y tener un claro discernimiento sobre funciones y cometidos.

44. Hay conceptos con los que, desde luego, no se puede sino estar de acuerdo. Extraigo del artículo titulado «Seguridad ciudadana», también contenido en el citado Diccionario latinoamericano de seguridad y geopolítica, las siguientes ideas plausibles.

[La seguridad ciudadana] es una superación del concepto de seguridad estatal, que privilegiaba el mantenimiento del orden público como valor máximo. Para la seguridad ciudadana la prioridad es la seguridad de las personas como un derecho exigible ante el Estado.

[...] aparece vinculada a otros ejes; por ejemplo, un orden ciudadano democrático, capaz de eliminar las amenazas de violencia en la población, que busca disminuir las nociones de vulnerabilidad y desprotección [...].

[...] es un derecho y a la vez un deber, posibilita la convivencia social y es factor de desarrollo en una sociedad.

[...] fue históricamente asignada a la jurisdicción de las fuerzas policiales exclusivamente, reduciéndola a técnicas reactivas de comportamientos ilegales, sin capacidad de desarrollar políticas preventivas sociales ni situacionales. 
Hoy se tiende a desarrollar una nueva perspectiva de la seguridad ciudadana, revirtiendo la visión de una sociedad víctima pasiva del azote criminal, para reconsiderar las potencialidades de la sociedad civil para enfrentarlo.

[...] el Estado debe equilibrar las contradicciones y la viabilidad de la economía con la dignidad de la persona humana y la protección social. Debe garantizar el acceso a la educación y a los valores que permitan que cada ser humano sea libre y respetado en un escenario de complejidad. Debe brindar un espacio público de calidad que posibilite el combate a la marginalidad y tener un sistema judicial moderno y ágil. Debe procurar la distribución social de la riqueza y el acceso al trabajo de calidad. (Barrios et al., 2009)

Son todos estos conceptos altamente compartibles, pero el problema es determinar cómo se hace para que se traduzcan en realidades y no sean una simple expresión declamatoria, que enuncia buenos deseos y apenas sirve para justificar posiciones burocráticas, sin que se consiga conjurar una situación crítica que la realidad concreta exhibe.

\section{En conclusión}

45. El Estado no puede renunciar al combate por la seguridad porque traicionaría su esencia, ni puede renunciar al uso legítimo de la fuerza por la misma razón. Tratándose de un problema complejo y multicausal, deberá atacarlo en sus diferentes frentes, incluyendo mecanismos de socialización, integración, educación y asignación de oportunidades, todo lo cual presupone la posibilidad de emplear recursos suficientes. Lleva mucho tiempo y hay un fuerte riesgo de fracasar.

Y entretanto se concreta la solución que mejore las cosas, blinde usted la puerta de su casa.

\section{Referencias bibliográficas}

ARonson, E. (1992). El animal social. Madrid: Alianza.

Barrios, M. A., Jaguaribe, H., Rivarola, A., Calduch Cervera, R. (2009). Diccionario latinoamericano de seguridad y geopolítica. Buenos Aires: Biblos.

BurdeAu, G. (1981). Derecho constitucional e instituciones políticas. Madrid: Editora Nacional.

CHURCHIL, W. (1941). Discurso.

Constitución de los Estados Unidos. Enmienda XVIII. Ratificada en 1919. 
Constitución de los Estados Unidos. Enmienda XXI. Ratificada en 1933.

Constitución de la República Oriental del Uruguay (1967). Asamblea General, Montevideo, Uruguay, 24 de agosto de 1966.

Foucault, M. (2016). Historia política de la verdad: Una genealogía de la moral. Breviario de los cursos del College de France. Madrid: Biblioteca Nueva.

FREUD, S. (2005). El malestar en la cultura. Madrid: Alianza.

HABERKORN, L. (25 de agosto de 2018). «Sergio Guarteche: Los narcos operan a piacere en Uruguay». El Observador. Recuperado de https://www.elobservador.com.uy/ nota/sergio-guarteche-los-narcos-operan-a-piacere-en-uruguay--2018825500.

HobBes, T. (1994). Leviatán: La materia, forma y poder de un Estado eclesiástico y civil. Barcelona: Altaya.

KUBRIK, S. (director). (1968). 2001: Odisea del espacio [película cinematográfica]. Reino Unido: Metro-Goldwyn-Mayer, Stanley Kubrick Productions.

LEVAL, G. (1978). El Estado en la historia. Madrid: Zero.

MiLgram, S. (1980). Obediencia a la autoridad: Un punto de vista experimental. Sevilla: Descleé de Brouwer.

ORWELL, G. (1949). 1984. Londres: Secker \& Warburg.

PEREYRA, G. (12 mayo de 2018). «Un día los marginados van a ser mayoría. ¿Cómo los vamos a contener?». El Observador. Recuperado de https://www.elobservador. com.uy/nota/-un-dia-los-marginados-van-a-ser-mayoria-como-los-vamos-acontener-2018512500.

RousSEAU, J. J. (2007). El contrato social. Madrid: Espasa Calpe.

SAYAguÉS LASO, E. (1988). Tratado de derecho administrativo. Tomo I. 6. ${ }^{\text {a }}$ ed. Montevideo: FCU.

SHEARING, C. \& Wood, J. (2011). Pensar la seguridad. Barcelona: Gedisa. 